\title{
IMPORTANCE AND IMPACT OF ONLINE COURSES FOR TRAINING PRIMARY HEALTH CARE PROFESSIONALS IN THE SCREENING, IDENTIFICATION, AND MANAGEMENT OF MAMMALIAN PATHOLOGIES/BREAST CANCER
}

Alexandre Villela de Freitas¹, Lucas Stathiacos e Castella², Carolina Abreu de Rezende², Ana Jéssily Camargo Barbosa ${ }^{3}$, Tânia Silva de Melo ${ }^{4}$

${ }^{1}$ Hospital Ministro Costa Cavalcanti - Foz do Iguaçu (PR), Brazil.

${ }^{2}$ Acadêmicos de Medicina, Centro Universitário das Américas - São Paulo (SP), Brazil.

${ }^{3}$ Coordenação da Educação Permanente, Atenção Básica da Secretaria de Saúde de Foz do Iguaçu - Foz do Iguaçu (PR), Brazil.

${ }^{4}$ Gerente do Programa de Saúde da Mulher, Secretaria de Saúde de Foz do Iguaçu - Foz do Iguaçu (PR), Brazil.

Introduction: Brazil is currently living in a scenario of epidemiological transition in health. Simultaneous occurrence of diseases is common to those of developed and underdeveloped countries, thus, facing a major challenge in planning and managing efficient public health policies that cover ongoing transitions. The increase in life expectancy leads to an increase in the incidence of chronic-degenerative diseases such as cancer. The use of the Internet for lectures, courses, and questionnaires, due to agility, low cost, wide reach, and excellent use of responses has been demonstrated as an excellent tool for research and teaching. Objective: The aim of this study was to assess the importance and impact of conducting online training courses for primary health care professionals in the screening, identification, and management of breast diseases/ breast cancer. Methodology: This is all cross-sectional and descriptive, carried out through the selection of 80 physicians and 100 nurses from primary health care in the municipality of Foz do Iguaçu by virtual communication and link to attend the course with mastological content elaborated from the Mastology Treaty of the Brazilian Mastology Society. Online lecture was held by shared platform with later discussion and clarification, application of a virtual questionnaire on the perception of the importance of the lecture content in their daily activities, and assimilation of the content. The value of the answers to the questionnaire was determined according to the profession and time of graduation. Results: We observed a higher access among nursing professionals when compared with physicians, $46 \% \times 28 \%$. The group of physicians, mean age of 39.7 years, ranging from 28 to 56 years, equally distributed between 3 and 5 years, 5 and 10 years, and more than 10 years were formed. Regarding nursing, the groups with mean age of 36.9 years, ranging from 23 to 57 years, predominantly professionals with more than 10 years were formed (60.9\%). All participants found this study useful or very useful for their professional activities. We observed a performance higher than $75 \%$ in correct answers to the questions in $61 \%$ and $56 \%$ of medical professionals and nurses, respectively, and close to $80 \%$ with performance higher than $50 \%$ in both groups. Among themselves related to the lowest rate of correct answers were the exclusion of self-examination as a measure of prevention and the higher rate are the indications of breast ultrasound complementary to mammography. Conclusion: Online courses for primary care professionals can be considered a useful tool in the training process, with low cost, good results, and great acceptance.

Keywords: Breast Cancer; Training; Tracking; Primary Health Care; Online. 